\title{
AVALIAÇÃO NUMÉRICA DA INTEGRIDADE ESTRUTURAL DE REVESTIMENTO DE POÇOS DE PETRÓLEO EM ZONAS DE ALTA PRESSÃO E ALTA TEMPERATURA E ÁREAS DE ROCHAS SALINAS
}

\author{
J. P. A. CORREIA* e J. P. L. SANTOS \\ Universidade Federal de Alagoas - Centro de Tecnologia - Engenharia de Petróleo \\ joaopaulocorreia@live.com ${ }^{*}$
}

Submetido 08/10/2016 - Aceito 06/03/2017

DOI: $10.15628 /$ holos. 2017.5178

\section{RESUMO}

As atividades de projeto e instalação de colunas de revestimento em poços de petróleo correspondem a elementos fundamentais para garantir a segurança e a operacionalização de campos exploratórios. Com o desafio da perfuração de poços em áreas geologicamente mais complexas, a exemplo das chamadas reservas do pré-sal e em reservatórios sujeitos à alta pressão e alta temperatura (High Pressure High Temperature - HPHT), novas variáveis de projeto devem ser consideradas. Este trabalho propõe-se a avaliar o comportamento de modelos constitutivos de rochas salinas por meios de curvas de fluências objetivando avaliar o impacto do efeito de fluência da rocha salina na estabilidade do poço aberto na fase de perfuração. Também são avaliados os incrementos de esforços advindos do comportamento viscoso das rochas salinas nas colunas de revestimento de poços de petróleo e a respectiva influência no tratamento de projetos para dimensionamento de revestimento de poços. Emprega-se uma estratégia baseada no método dos elementos finitos para modelar o comportamento de fluência em rochas salinas através de modelos viscoelásticos em função da série de Pronny. O processo de dimensionamento das colunas de revestimento é efetuado seguindo as recomendações normativas da API5C3 e ISO10400.

PALAVRAS-CHAVE: Revestimento de Poços de Petróleo, Fluência de Rochas Salinas, HPHT, Projetos de Poços de Petróleo.

\section{NUMERICAL EVALUATION OF STRUCTURAL INTEGRITY OF OIL WELLS CASING IN HIGH PRESSURE AND HIGH TEMPERATURE AND SALT ZONES.}

\section{ABSTRACT}

The desing and installation of the casing wells correspond of key elements to ensure the safety and operation of exploratory fields. With the challenge of drilling in geologically complex areas, like pre-salt and reservoirs subject to high pressure and high temperature (High Pressure High Temperature - HPHT), new variables in projects should be considered. This work proposes to evaluate the behavior of constitutive models fluencies in salt rock, and then determine empirical models by means of creep curves. Also are evaluated the increments efforts from the viscous behavior of the salt rocks in the casing of oil well and its influence on the treatment for wells designs. It is used a strategy based on the finite element method to model the creep behavior salt rock through viscoelastic models depending based of Pronny' series. The design process for casing following the standard recommendations of API5C3 and ISO10400.

KEYWORDS: Oil wells casing, Salt rocks fluency, HPHT, Oil wells project. 


\section{INTRODUÇÃO}

Umas das principais etapas durante o processo de desenvolvimento de poços de petróleo é a operação de revestimento do poço. Esta operação ocorrer através da descida de colunas de aço. As colunas de revestimento são geralmente instaladas após o procedimento de perfuração, ou até mesmo durante a perfuração, e possuem o objetivo de garantir, principalmente, a estabilidade das paredes laterais do poço para prosseguimento da perfuração em fases mais profundas, bem como garantir o isolamento do poço com relação ao meio externo (Bernt, 2010).

Atualmente, com a descoberta de campos em áreas geologicamente mais complexa, como exemplo as reservas do pré-sal e reservatórios sujeitos à alta pressão e alta temperatura (HPHT), novas variáveis de projetos devem ser consideradas no processo de dimensionamento das colunas de revestimento.

Uma das dificuldades na perfuração através de rochas salinas corresponde à característica reológica do material geológico (sal in situ), que mesmo quando sujeito a esforços de tensão constante, apresenta níveis de deformações variáveis em função do tempo e das condições de carregamento, fenômeno este conhecido pela terminologia fluência. Esta é a principal diferença no comportamento mecânico em relação às demais rochas sedimentares.

De forma mais crítica, depois de revestido, as colunas de aço empregadas no revestimento do poço também estarão sujeitas ao incremento do campo de tensões provocados pelo efeito de fluência da rocha salina. Tal configuração poderá induzir a grandes alterações na distribuição de tensões ao redor do revestimento, que devem ser previstas no processo de dimensionamento das colunas de revestimento.

O objetivo deste trabalho é avaliar os modelos constitutivos de fluências de rochas salinas e seus consequentes incrementos de esforços induzidos nas colunas de revestimento de poços de petróleo, de modo a considerá-los em projetos de revestimento, procurando garantir a segurança de operação e, sobretudo, a integridade estrutural da coluna.

\section{REVISÃO BIBLIOGRÁFICA}

\subsection{Projetos de Revestimento de Poços de Petróleo}

$\mathrm{Na}$ etapa de perfuração de poços de petróleo é conveniente revestir o poço através da descida de colunas de aço para garantir a segurança e prosseguimento das outras etapas de produção petrolífera. O projeto das colunas de revestimento de poços de petróleo é iniciado com os cálculos de esforços atuantes nos mais diversos cenários das formações que possam surgir no desenvolvimento do poço. De posse desses esforços, são calculadas as resistências mecânicas dos tubos. Um projeto de coluna de revestimento deve garantir a integridade mecânica do poço e otimização dos custos totais envolvidos, com o uso de tubos que possuem as dimensões mínimas possíveis, e satisfazendo as devidas condições de operação (Costa \& Santos, 2015).

As colunas de revestimento em poços de petróleo estão sempre sujeitas a um estado combinado de tensões, seja de tração ou compressão com pressão interna ou externa, tal que 
representa a situação física mais próxima da realidade. Isto é chamado de estado combinado de esforços triaxial.

O método triaxial de esforços combinados é orientado através da elipse de tensões de von Misses e da envoltória API (construída com base em limites de segurança). De acordo com Bernt (2010), a elipse de tensões de von Misses define os limites de tensão axial versus pressão interna ou externa dentro do qual um tubo de revestimento deve estar operando no regime elástico, enquanto a elipse da envoltória API define uma região dentro do qual o tubo não falha, considerando as resistências à tração, pressão interna e colapso definidas com base em valores de segurança. Para o esforço de colapso, a envoltória API considera ainda a redução devida à tração.

Nos projetos de dimensionamento das colunas de revestimento devem-se considerar as resistências mínimas dos tubos para suportar os esforços solicitantes de tração, pressão interna (Burst), pressão externa (colapso) (Bernt, 2015). Para estimar tais valores de esforços, levam-se em conta as condições mais adversas que possam surgir durante a descida, a instalação e a vida útil das colunas e, no caso específico do trabalho, o esforço adicional em função da fluência da rocha salina.

\subsubsection{Esforço de tração}

O esforço do carregamento axial total em qualquer ponto da coluna deve considerar as condições de peso próprio da coluna, efeito de empuxo, carregamentos de flexão, overpull, carregamentos devido às mudanças de temperatura, dentre outros.

O cálculo da resistência à tração baseia-se na carga axial mínima requerida para o escoamento do tubo, de modo que o tubo não sofre deformações plásticas. Para sua quantificação, considera-se então a tensão de escoamento do aço como valor limite, na forma da Equação (1).

$R_{t}=\frac{\pi}{4}\left(D^{2}-d^{2}\right) Y_{p}$

Da Equação (1), temos que $D$ o diâmetro externo do tubo, $d$ o diâmetro interno do tubo e $Y_{p}$ o limite de escoamento do aço. O fator de segurança varia entre 1,1 à 1,6, dependendo das normas internas das operadoras.

\subsubsection{Esforço de pressão interna (Burst)}

O esforço de pressão interna, também conhecido como Burst, é o resultante do diferencial entre as pressões no interior e no anular, como resultado da pressão interna ser superior a pressão externa. A resistência à pressão interna $R_{p i}$ de escoamento no corpo do tubo de aço, expressada na Equação (2), é alcançada através da equação de Barlow, considerando $87,5 \%$ do escoamento da parede, pois a API permite a espessura variar em até $12,5 \%$, devido aos defeitos de construção, conforme discutido por Bernt (2010). 


$$
R_{p i}=0,875 * 2 Y_{p} * \frac{t}{D}
$$

Pela a Equação (2), segue que $Y_{p}$ o limite de escoamento do aço, $t$ a espessura do tubo e $D$ o diâmetro externo nominal do tubo. Para a resistência à pressão interna, o fator de segurança varia entre 1,0 a 1,25, também dependendo das normas internas das operadoras, assim como a resistência a tração.

Segundo Bernt (2010), um tipo de falha por esforço de pressão interna apresenta como característica uma falha ou propagação de trincas na direção predominante axial do tubo.

\subsubsection{Esforço de pressão externa (Colapso)}

A resistência ao colapso do revestimento indica o grau de limite de tensão suportado pelo revestimento devido ao diferencial das pressões criadas pelo fluido no anular e no interior da coluna, ou seja, verifica a possibilidade de falha quando a pressão externa é superior a pressão interna. A resistência ao colapso $R_{c}$ está em função da razão $D / t$, que relaciona o diâmetro e espessura, do grau do aço e do esforço axial característicos do tubo a ser empregado. Para o esforço do colapso, deve-se admitir um fator de segurança variante entre 1,0 a 1,125.

Segundo a normativa AMERICAN PETROLEUM INTITUTE [API] TR 5 C3 (2008), a resistência ao colapso está definido em 4 (quatro) tipos de regimes de falha: colapso de escoamento, colapso plástico, colapso de transição e colapso elástico, que são indicados através de uma faixa em função da razão $R_{p i}$. Esquematicamente, os regimes de falha ao colapso podem ser representados na Figura 1.

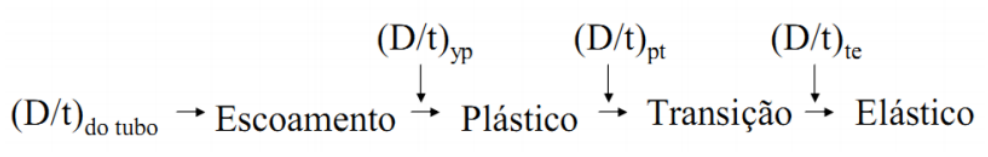

Figura 1 - Esquema dos regimes de falhas por colapso.

Deve-se também levar em consideração a influência da ação de esforço axial na resistência a pressão por colapso. Sabe-se que ocorre uma diminuição do limite de escoamento quanto da presença de esforços de tração, o que resulta numa diminuição da resistência ao colapso, segundo os procedimentos da API BULL 5C3 (1994), conforme mostrada na Equação (3).

$Y_{p a}=Y_{p} \sqrt{1-0,75\left(S_{a} / Y_{p}\right)^{2}-0,5\left(S_{a} / Y_{p}\right)}$

A Equação (3) é baseada na teoria da máxima energia de distorção de Hencky-von-Mises. A norma API TR 5C3 (2008) afirma que o material escoa quando a tensão equivalente de vonMises, obtida através da teoria máxima energia de distorção, supera o limite de escoamento do aço do casing $\left(\sigma_{V M E}>Y_{p}\right)$. 
Uma falha por pressão externa pode ser consequência de alterações da pressão de poro do reservatório, do fluido de perfuração e/ou da expansão térmica de gases no tubo.

Os procedimentos para o cálculo da resistência mecânica do tubo empregado no revestimento do poço de petróleo utilizado nesse trabalho seguem às orientações normativas da norma API Bull 5C3 (2008).

A segurança estrutural das colunas de revestimento também deve estar associada ao estado limite. Quando a integridade estrutural, um estado de limite é definido quando uma estrutura deixa de obedecer a qualquer das finalidades de sua construção, e este pode ser estado limite último e estado limite de serviço.

O estado limite último (ELU) corresponde ao esgotamento da capacidade portante, associado ao colapso provocando a paralisação do uso. Pode ser ocasionado por ruptura de seções críticas da estrutura, colapso da estrutura, perda da estabilidade do equilíbrio e deterioração por fadiga (Bittencourt \& Souza, 2015).

O estado limite de serviço (ELS) está associado à durabilidade e bom desempenho funcional. Pode ser exemplificado através das deformações e deslocamentos excessivos para utilização normal da estrutura, fissuração prematura ou excessiva, danos indesejáveis (como corrosão, por exemplo), deslocamentos excessivos sem perda da estabilidade e vibrações excessivas (Bittencourt \& Souza, 2015).

Os conceitos de estado limite último e estado limite de serviço são métodos aplicados para verificação da segurança de desempenho estrutural de modo a majorar as ações dos esforços solicitantes, ou seja, permitir que os esforços resistentes de projeto sejam maiores ou iguais aos esforços solicitantes de projeto.

\subsection{Exploração de Poços de Petróleo HPHT e em Áreas de Rochas Salinas}

Conforme Auwalu, Zahra, Adamu, Usaman e Sulaiman (2015), umas das principais características de poços de petróleo HPHT é a existência de pequena margem entre a pressão dos poros e a pressão de fratura, bem como a elevada temperatura no fundo do poço, tal que representa um grande desafio tanto para o gerenciamento do fluido de perfuração quando na condição de fundo de poço e incidentes de controle.

A rocha salina in situ apresenta comportamento parcialmente viscoso e tende a fluir durante o processo de perfuração podendo ocasionar o fechamento das paredes laterais do poço, gerando estados de solicitações de tensões que devem ser inclusos no cálculo de dimensionamento das colunas de revestimento (Santos, 2011).

O comportamento reológico do sal segue um modelo de fluência clássico constituído basicamente por uma fase transiente, caracterizado por uma elevada taxa de deformação logo após a aplicação de uma carga constante, e por uma fase estacionária, que tende a diminuir a taxa de deformação em função do rearranjo molecular está se aproximando de um valor constante, mas novos incrementos de deformação acontecem com o aparecimento de microfissuras, e retoma o ciclo clássico de fluência salina (Findley, Lai \& Onaran, 1976).

A curva de fluência em rochas salinas, conforme ilustrada na Figura 2, tem grande dependência da intensidade da tensão aplicada e das condições de temperatura, assim como 
também dependência da espessura da camada de sal, do gradiente geotérmico, da composição mineralógica, do conteúdo de água da presença de impurezas e pela extensão na qual as tensões diferenciais são aplicadas ao sal (Costa, Poiate \& Falcao, 2005).

Figura 2 - Modelo clássico de fluência salina.

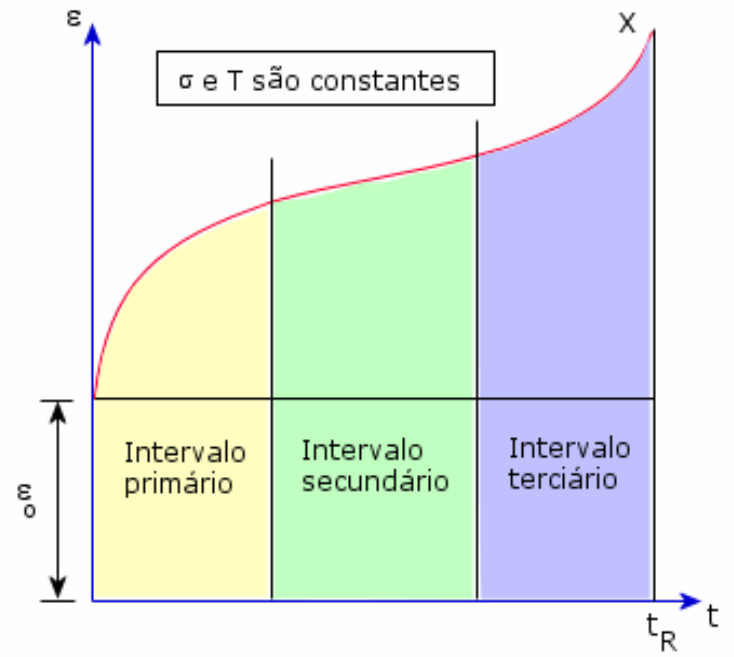

Fonte: Costa, Poiate e Falcao (2005).

A aplicação da simulação numérica para a reologia das rochas salinas, em especial durante o processo de perfuração, pode ser obtida por meio do emprego do modelo reológico do sólido viscoelástico padrão. O modelo mais difundido associa um elemento de Maxwell em paralelo. Partindo da equação integral do modelo viscoelástico linear, pode-se reescrever a expressão para a parcela desviatória do tensor de tensões $s$ em função da deformação desviatória e na forma da Equação (4), como mostra Rahman e Chilingarian (1995).

$s(t)=\int_{-\infty}^{t} 2 G(t-\tau) \frac{\partial e}{\partial \tau} \partial \tau$

Através da formulação expressão na Equação (4), é possível particularizar a representação final para um fluido e um sólido viscoelásticos. Partindo da forma integral da Equação (4), obtémse uma função de relaxação $G$ de tal maneira que o modelo do sólido viscoelástico é atendido. Uma solução particular é a chamada série de Pronny, conforme mostra-se na Equação (5), onde $\mu_{o}$ e $\mu_{N}$ são os parâmetros adimensionais ajustados com dados experimentais e $\lambda_{N}$ é o tempo de relaxação.

$\bar{G}(t)=G_{o}\left[\mu_{o}+\sum_{t=1}^{N} \mu_{N} e^{-\frac{t}{\lambda_{N}}}\right]$ 


\section{METODOLOGIA}

Os parâmetros da função de fluência empregados para o modelo viscoelástico foram calibrados por meio do método dos mínimos quadrados com base em dados de ensaios triaxiais em corpos de prova de rochas salinas extraídas da mina Taquari Vassouras (SE), realizados por D’Elia (1991). Esses parâmetros refletem a fluência estacionária em rocha salina sob alta pressão e alta temperatura, particularmente representadas aos termos da série de Pronny.

A estratégia numérica para representar o estado de deformação da rocha salina em função do tempo é baseada em um esquema recursivo proposto por ZIENKIEWICZ [2005] com base num esquema de marcha no tempo baseado em diferença central.

O cenário para aplicação da simulação numérica da perfuração de um poço numa camada de sal está mostrado na Figura 3.

Figura 3 - Cenário de estudo.

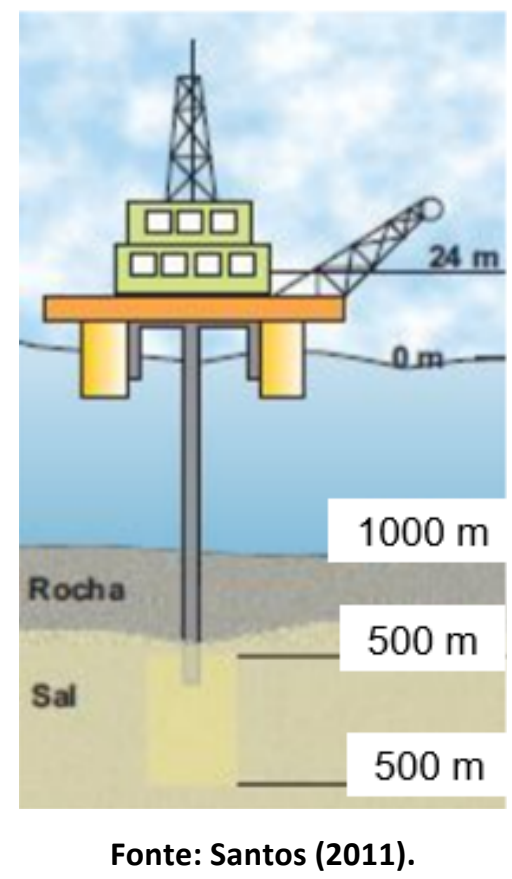

O modelo geológico adotado é caracterizado por apresentar três camadas de estruturas geológicas, como mostrada na Tabela 3. Segundo Teng, Yang, Li, Yu, Jin, e Chen (2015), a presença de uma zona acima, ou abaixo, de uma formação salina tem que ser cuidadosamente concebida, pois essa zona pode ter gradientes muito baixos de fratura e, com isso, uma perda de circulação na perfuração do poço pode se desenvolver devido a uma falha de tração levando à fratura da zona.

Tabela 1: Cenário de estudo.

\begin{tabular}{c|c|c}
\hline $\begin{array}{c}\text { Tipo de } \\
\text { camada }\end{array}$ & $\begin{array}{c}\text { Peso específico } \\
\left(\mathrm{kN} / \mathrm{m}^{2}\right)\end{array}$ & Espessura $(\mathrm{m})$ \\
\hline Lâmina d'água & 10,18 & 1000 \\
Rocha dura & 22,56 & 500 \\
Rocha salina & 21,60 & 500 \\
\hline
\end{tabular}


A estratégia de solução tanto para o modelo elástico linear quanto para o modelo viscoelástico empregada nesse trabalho é baseada no método dos elementos finitos com auxílio do software ABAQUS (2007). Adota-se para implementação das formulações descritas elementos quadriláteros bilineares (Q4).

Os procedimentos de cálculo de cargas resultantes seguem às recomendações normativas, admitindo o estado combinado dos esforços, considerando, sobretudo a influência dos esforços axiais sobre as resistências ao colapso e pressão interna nos tubos de revestimento. Esses procedimentos seguem as orientações normativas da API TR 5C3 (2008). Para análise de resistência mecânica do revestimento são utilizadas as recomendações normativas da API5C3 [2008] com auxílio do software CWELL (2015), em desenvolvimento na Universidade Federal de Alagoas. A estratégia permite a avaliação integrada da resistência ao colapso, pressão interna e esforço axial.

\section{RESULTADOS E DISCUSSÕES}

\subsection{Modelos Constitutivos de Rochas Salinas}

O primeiro passo na representação numérica da reologia do sal está relacionado à definição dos parâmetros relacionados à fluência da rocha salina. D'Elia (1991) mostrou que a avaliação do comportamento de fluência das rochas salinas pode ser feita através dos níveis de deformação em função do tempo. A Figura 4 apresenta os níveis de deformação para a amostra de rocha salina taquidrita (HC-12) do maciço da mina Taquiri-Vassouras de Sergipe aplicadas para uma tensão variável em um período de $100 \mathrm{~h}$.

A equação empírica, aplicada no ajuste, é uma equação matemática governante do tipo exponencial, que num formato geral está mostrada na Equação (6), sendo $d(t)$ a deformação por fluência no tempo; $t$ o tempo; $a, b$, e $c$ são parâmetros da equação constitutiva de deformação.

$d(t)=a\left(b-e^{-c t}\right)$

A Tabela 2 apresenta os coeficientes dos parâmetros obtidos no ajuste para a curva de deformação pela tensão aplicada na amostra.

Tabela 2: Coeficientes da equação constitutiva de fluência.

\begin{tabular}{c|c}
\hline $\begin{array}{c}\text { Parâmetro } \\
\text { constitutivo }\end{array}$ & Valor \\
\hline a & 0,01192 \\
b & 1,18719 \\
c & 0,02828 \\
\hline
\end{tabular}

Para compatibilizar o modelo a ser desenvolvido com os estudos feitos por D'ELIA [1991], os parâmetros encontrados na Tabela 2 foram ajustados para uma função de relaxação baseados 
nos níveis de deformações da Figura 4 para então associa-los aos termos da série de Pronny, conforme mostrado na equação (5).

$\mathrm{Na}$ simulação numérica, considerou-se o fluido de perfuração hidrostático com massa específica de 10,5 lb/gal. A malha de elementos finitos é constituída por 630 elementos quadriláteros lineares (Q4), e não estrutura.

Também na Figura 4 apresenta os níveis de deformação para o modelo viscoelástico em um ponto localizado na parede do poço perfurado na zona de sal, o que induz a um incremento de esforço de colapso de $0.215 \mathrm{Mpa}$ no revestimento do poço. Considera-se na simulação a rocha salina com coeficiente de Poisson de 0.36 e a tensão de sobrecarga correspondente ao peso próprio das camadas adjacentes.

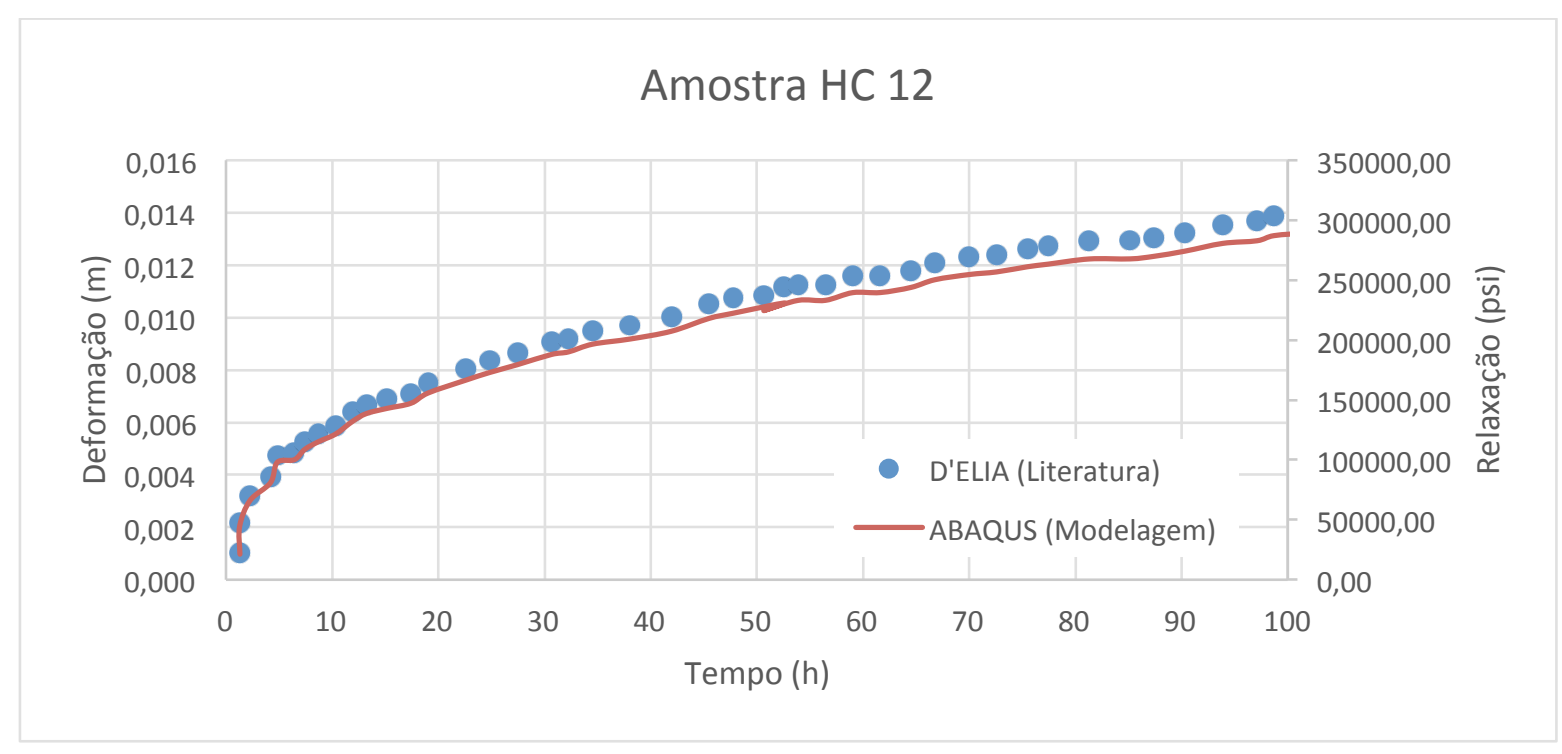

Figura 4: Evolução temporal das deformações.

De acordo com a Figura 4 pode-se notar que os resultados das curvas de deformação obtidos indicam boa coerência do modelo clássico de deformação, ou seja, uma elevada deformação nos instantes iniciais e uma tendência a ser constante nos tempos posteriores tanto no modelo descrito pela literatura de D’Elia (1991) quanto pela modelagem viscoelástica no ABAQUS.

O nível de tensão adicional provado pelo efeito da reologia do sal será transmitido ao revestimento do poço, devendo então o mesmo ser dimensionado para suportar esses efeitos adicionais.

Também é necessário avaliar a taxa de deformação por fluência da rocha salina taquidrita a poço revestido de acordo com o que é mostrado na Figura 5, após a simulação feita no ABAQUS. 


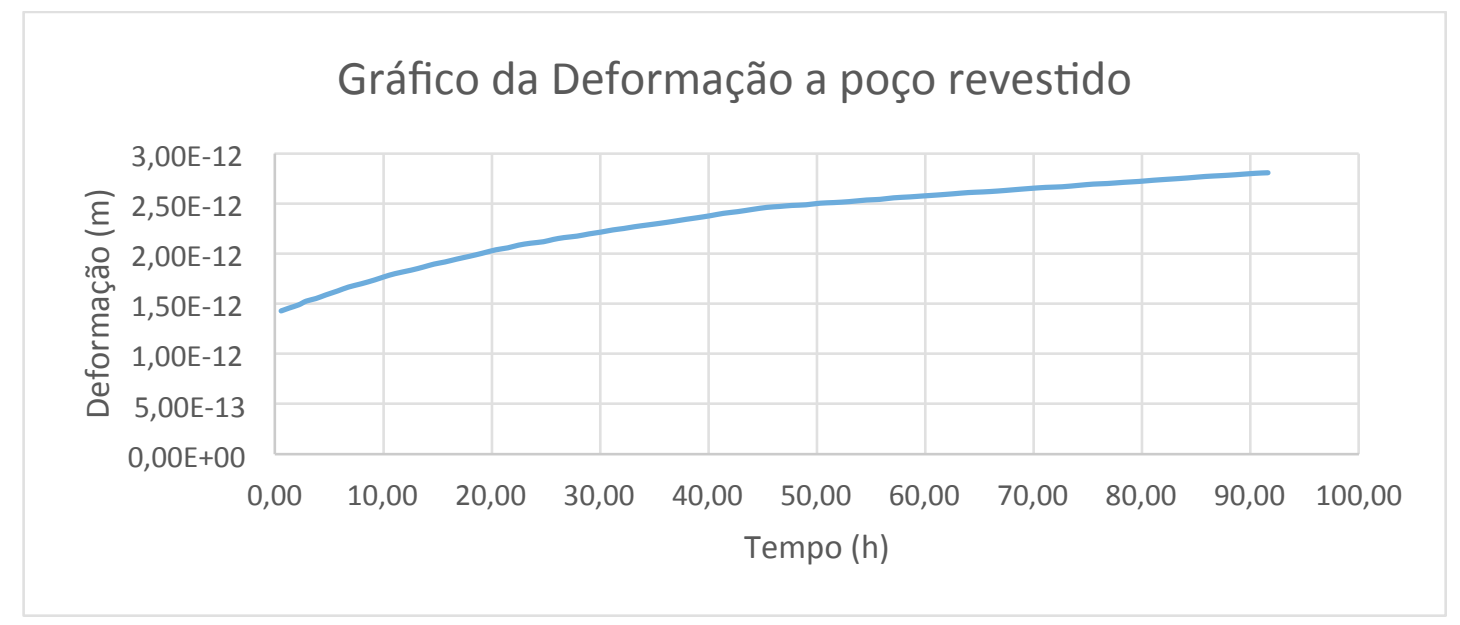

Figura 5: Gráfico de deformação a poço revestido.

A partir dos dados de deformação apresentados na Figura 5, é possível calcular o esforço de colapso induzido provocado pela fluência da rocha salina taquidrita no revestimento. Considera-se o módulo de elasticidade de 2,07×107 kPa. A tabela 3 apresenta os esforços inicial e final para a curva de fluência da Figura 5.

Tabela 3: Deformação e esforços induzidos pela fluência.

\begin{tabular}{c|c|c}
\hline Estado & Deformação & Esforço (psi) \\
\hline Inicial & $1,42 \mathrm{E}-12$ & 4206,09 \\
Final & $2,81 \mathrm{E}-12$ & 8412,18 \\
\hline
\end{tabular}

Os esforços induzidos mostrados na Tabela 3 devem ser considerados no dimensionamento das colunas de revestimento seguindo as recomendações normativas.

\subsubsection{Efeito do fluido de perfuração}

Segundo Santos (2011) uma alternativa para lidar com o fenômeno de fluência das rochas salinas é aumentar o peso específico do fluido durante a operação de perfuração de poços de petróleo. Isso é justificado pelo fato de que as tensões radiais geradas pela pressão do fluido de perfuração ajudam a contrabalancear os esforços provocados pela fluência da rocha salina.

Sendo assim, é avaliado o comportamento de fluência na parede do poço empregando fluidos de perfuração com pesos específicos de 10,5 lb/gal, 12,0 lb/gal e 13,5 lb/gal, conforme-se mostra na Figura 6 com o modelo reológico da rocha salina taquidrita. 


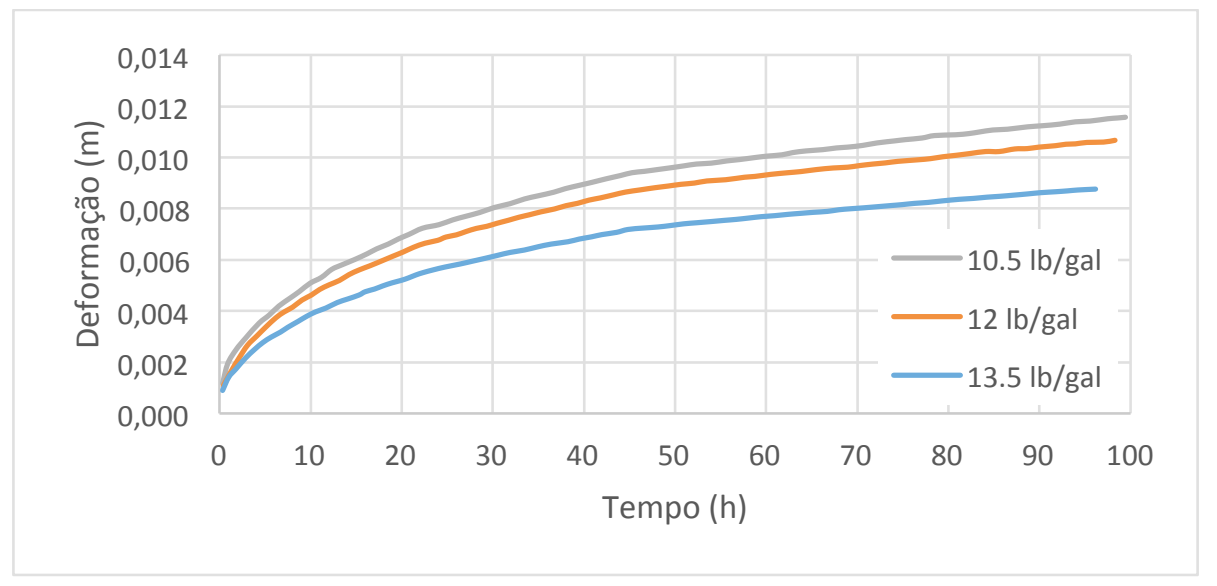

Figura 6: Deformação vs tempo para fluidos de perfuração distintos na parede do poço.

A partir da Figura 6, percebe-se que quanto maior for o peso fluido de perfuração, maior será o tempo de trabalho antes de se atingir a deformação limite ou aceitável. O fluido de perfuração 13,5 lb/gal permite uma operação de maior tempo do que o fluido de operação de 10,5 lb/gal, isso considerando a mesma taxa de deformação. Assim, de acordo com Teng, Yang, Li et al. (2015) e Auwalu, Zahra, Adamu et al. (2015), pode ser então possível perfurar um poço em área salina com um fluido de perfuração de solução salina saturada para ampliar o furo do poço, e evitar sub-fresagem antes do revestimento.

\subsection{Dimensionamento das colunas de revestimento}

Para análise de resistência mecânica do revestimento são empregadas às recomendações normativas da API Bull 5C3 (1994), com auxílio do software CWELL (2015), em desenvolvimento na Universidade Federal de Alagoas. A estratégia permite a avaliação integrada da resistência ao colapso, pressão interna e esforço axial.

Para análise do cenário de possibilidade de falha por colapso no revestimento do poço sob efeito de rocha salina, considera-se 3 três tipos de cenário, conforme se mostra na Tabela 4.

Tabela 4: Cenários para análise de possiblidade de falha por colapso no revestimento.

\begin{tabular}{c|c|c|c}
\hline Cenário & Grau do aço & $\begin{array}{c}\text { Tensão de } \\
\text { escoamento (ksi) }\end{array}$ & $\begin{array}{c}\text { Diâmetro } \\
\text { externo (in) }\end{array}$ \\
\hline C1 & L80 & 80 & 9,625 \\
C2 & Q125 & 125 & 9,625 \\
C3 & V150 & 150 & 9,625 \\
\hline
\end{tabular}

O diâmetro externo do tubo de revestimento foi adotado de $95 / 8^{\prime \prime}$, pois considerou-se uma coluna de revestimento de produção, que tem como funções permitir a produção do poço suportando as paredes e isolando os intervalos produtores.

As Figuras 7, 8 e 9 apresentam as envoltórias de resistência para os cenários indicados na Tabela 4 para avaliação do cenário de possibilidade de falha por colapso no revestimento do poço sob efeito de fluência da rocha salina. Essas envoltórias correspondem as curvas de von Misses e da API, seguindo as recomendações normativas para dimensionamento das colunas de 
revestimento considerando o estado combinado de tensões adicionado ao fator de segurança. Além das curvas de envoltórias, nas Figuras 7, 8 e 9 temos que o ponto preto e o ponto vermelho significam, respectivamente, os esforços inicial e final, mostrados na Tabela 3.

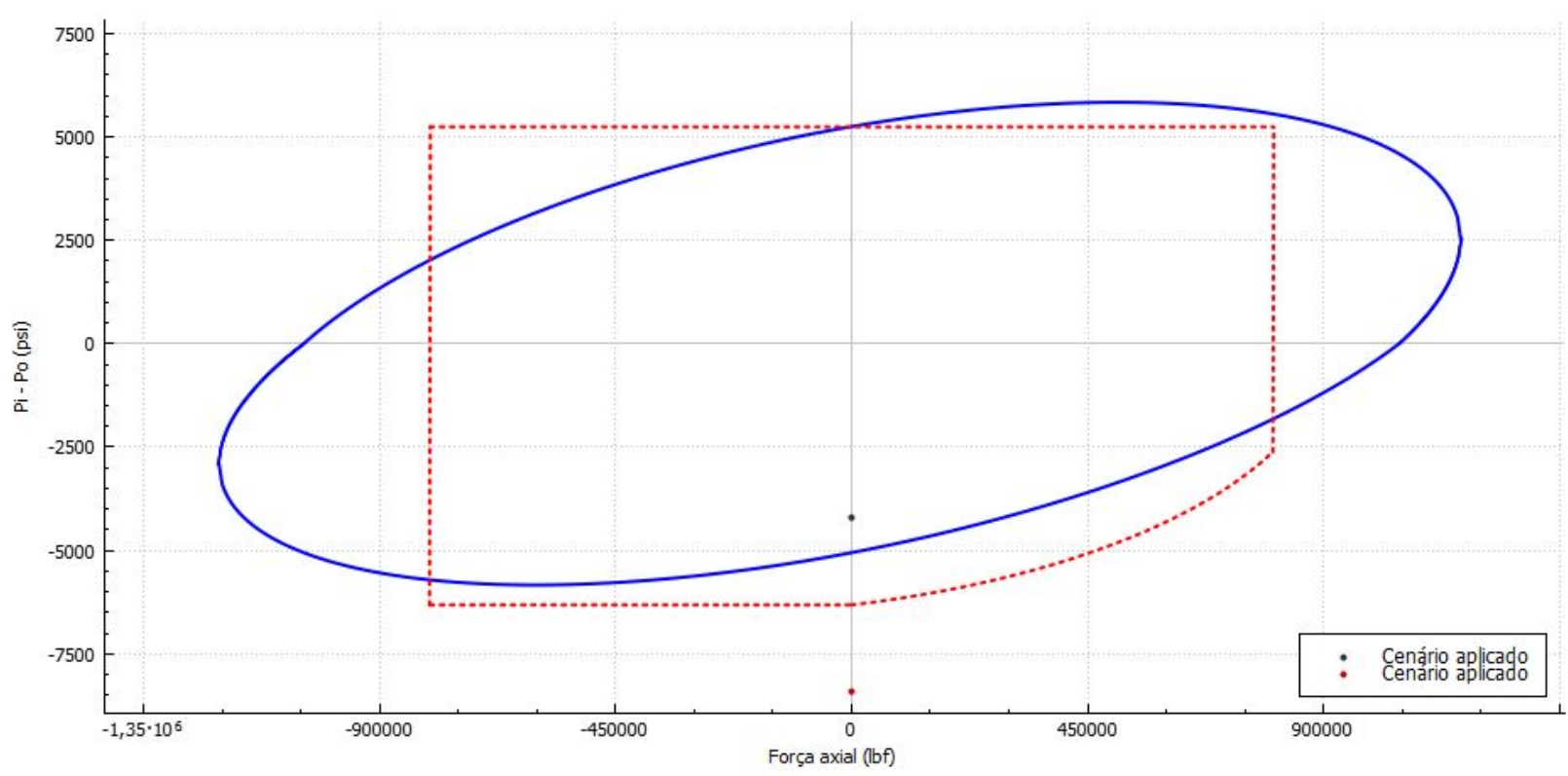

Figura 7: Envoltória de resistência para o cenário C1.

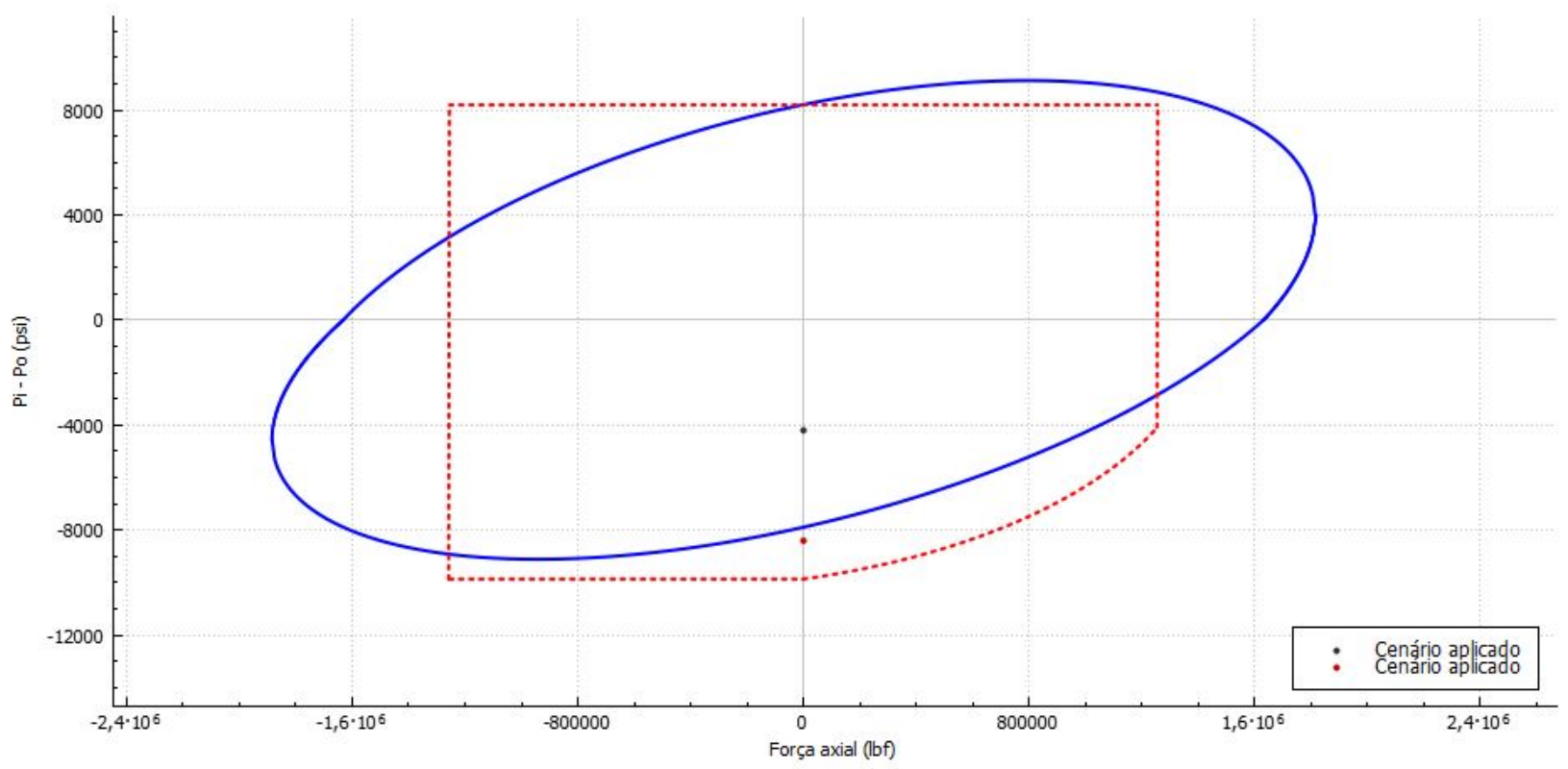

Figura 8: Envoltória de resistência para o cenário C2. 


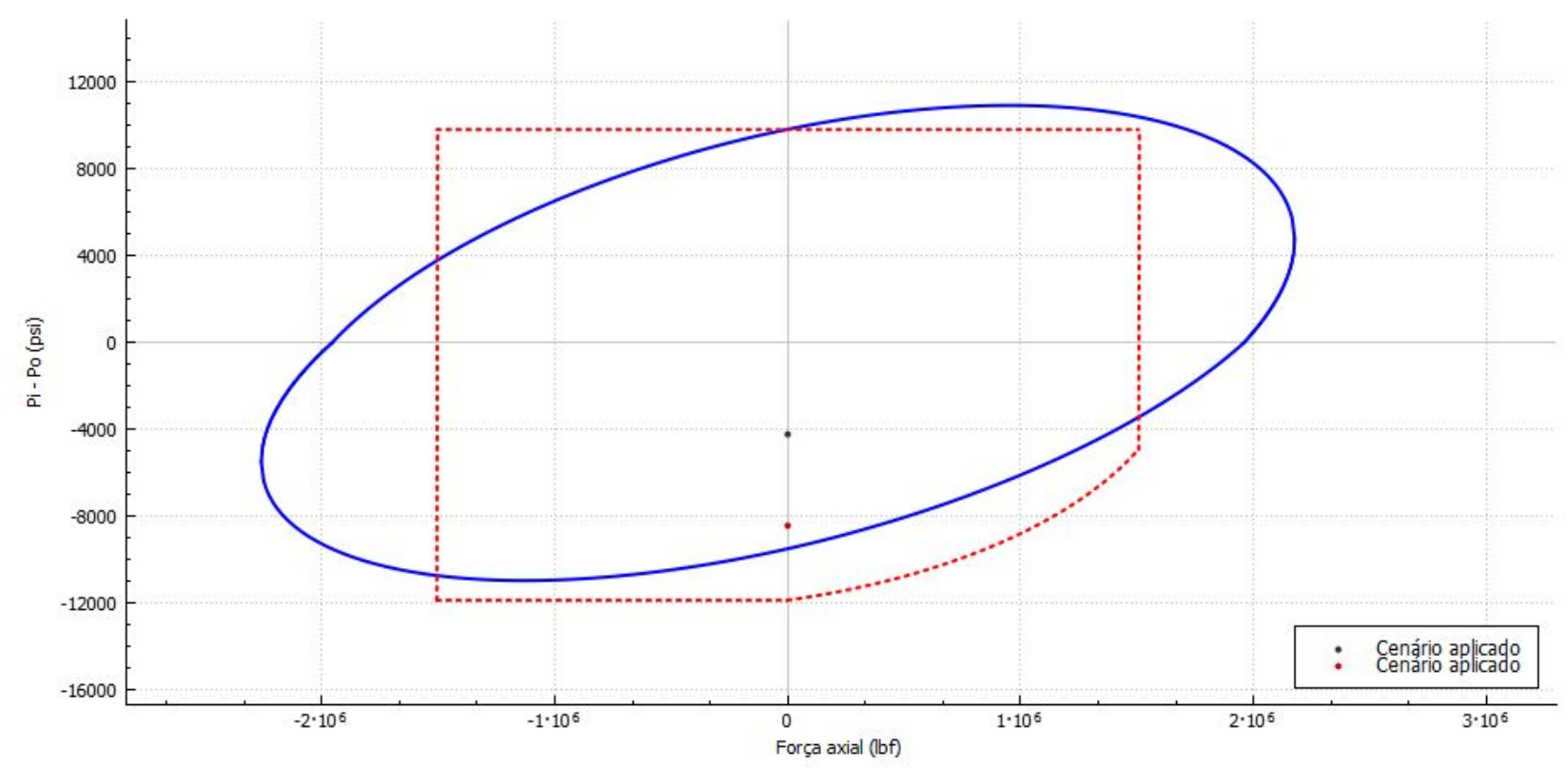

Figura 9: Envoltória de resistência para o cenário C3.

De acordo com a Figura 7, o cenário C1 (tubo L80) falha por colapso sob influência do efeito de fluência salina, pois o esforço final não é suportado no revestimento proposto tanto na envoltória von Misses quanto na envoltória da API. Logo, o cenário C1 da Figura 7 indica que o tubo escolhido não deve ser utilizado para revestir o poço, devendo-se escolher outro tubo com melhores níveis de resistência.

Já pela Figura 8, o cenário C2 (tubo Q125) não falha para o regime de colapso de fluência salina, porém opera no limite de segurança, uma vez que o esforço final está entre as envoltórias von misses e da API. Assim, pode-se utilizar o cenário 2 da Figura 8, porém não é recomendado, tampouco seguro.

Pela Figura 9, o cenário C3 (tubo V150) não falha por colapso sob o efeito de fluência salina, pois a coluna em toda sua integridade suporta os esforços oriundos da rocha salina, uma vez que os esforços inicial e final estão dentro das envoltórias de von Misses e da API, e opera no limite de segurança estabelecidos pelas normativas. Portanto, o cenário C3 apresentado na Figura 9 é recomendo e seguro para aplicação do modelo constitutivo da rocha salina.

\section{CONCLUSÃO}

O efeito de fluência induzida pela rocha salina propaga tensões adicionais de colapso no revestimento do poço que devem ser avaliadas. No caso em estudo, as estratégias numéricas adotadas se mostram coerentes para análise desses efeitos adicionais, garantindo, portando a integridade estrutural dos poços.

O controle do peso do fluido de perfuração é importante para garantia de margem de operação necessária para instalação de colunas para revestir o poço aberto na seção de rocha salina.

A análise dos fatores de segurança para diferentes condições de grau de aço como coluna de revestimento do efeito de fluência também se apresenta como um aspecto bastante positivo 
para avaliação da aplicabilidade das colunas de revestimento nos poços de petróleo como forma de segurança.

\section{REFERÊNCIAS}

ABAQUS. (2007). Manual Version 6.7. Student Version, Hibbitt Karlsson \& Sorenssen, Inc.

AMERICAN PETROLEUM INSTITUTE. (1994). API Bull 5C3: Bulletin on Formulas and Calculations for Casing, Tubing, Drill Pipe, and Line Pipe Properties.

AMERICAN PETROLEUM INSTITUTE. (2008). API/TR 5C3: Technical report on equations and Calculations for Casing, Tubing, and Line Pipe Used as Casing, or Tubing; and Performance Properties Tables for Casing and Tubing.

AUWALU, I. M., ZAHRA, I. Z., ADAMU, M. B., USMAN, A. L., SULAIMAN, A. D. (2015). Effectiveness of Simulations on Well Control during HPHT well drilling. Lagos, Nigeria, Society of Petroleum Engineers.

BERNT, S. A. (2010). Modern Well Desing. 2 ed. CRC Press. Slavanger, Norway, University of Slavanger.

BITTENCOURT, T. N., SOUZA, R. A. (2015). Introdução à Segurança das Estruturas. São Paulo, SP, Faculdade de Engenharia São Paulo - Laboratório de Estruturas e Materiais Estruturais.

CWELL. (2015). Software de Dimensionamento de Revestimento de Poço. Maceió, Alagoas, Universidade Federal de Alagoas - Laboratório de Computação Cientifica e Visualização.

COSTA, A. M., POIATE, E. J., FALCAO, J. L. (2005) Triaxial Creep Test in Salt Applied in Drilling Thick Slat Layers in Campos Basin. Amsterdam, The Netherlands, In: Paper SPE 92629, Presented at SPE Drilling Conference.

D'ELIA, P. C. (1991). Análise e Retro Análise do Comportamento de fluência em Escavações Subterrâneas pelo Método dos Elementos Finitos. Rio de Janeiro, RJ, Programa de Pós-graduação de Engenharia da Universidade Federal do Rio de Janeiro. COPPE/UFRJ.

FINDLEY, W. N., LAI, J. S., ONARAN, K. (1976). Creep and Relaxation of Nonlinear to linear Viscoelastic Materials with an Introduction to Linear Viscoelastic. Amsterdam, North-Holland, Engineering Brown University.

COSTA, J. C. H., SANTOS, J. P. L. (2015). Ferramenta Computacional para Auxílio ao Dimensionamento de Colunas de Revestimento de Poços de Petróleo. Rio de Janeiro, RJ, XXXVI Ibero-Latin American Congress on Computational Methods in Engineering - CILAMCE.

RAHMAN, S. S., CHILINGARIAN, G. V. (1995). Casing Design Theory and Practice. Amsterdam, North-Holland: Elsevier - Developments in Petroleum Science.

SANTOS, J. P. L. (2011). Estratégias Adaptativas para Formulações Mista em Elementos Finitos Aplicadas a Modelos Reológicos Viscoelásticos e Modelos Lineares Incompressíveis. Rio de Janeiro, RJ, Programa de Pós-Graduação em Engenharia Civil da Universidade Federal do Rio de Janeiro (COPPE/UFRJ).

TENG, X., YANG, P., LI, N., YU, F., JIN, Y., CHEN, M. (2015). Successful HPHT Drilling Through Innovative Practices: Sharing The Subsalt HPHT well Drilling Case in Tarin Basin. Manama, Bahrain, Society of Petroleum Engineers. 